\title{
Brown Field Project SCADA pada Pengoperasian Mixing Tank Hemodialisa di PT Sanbe Farma
}

\author{
Dede Furqon Nurjaman, S.T., M.T. ${ }^{1}$, Naftalin Winanti, S.ST., M.T ${ }^{2}$ \\ ${ }^{1}$ Jurusan Teknik Elektro, Universitas Jenderal Achmad Yani, Cimahi 40513 \\ E-mail :dede.furqon@lecture.unjani.ac.id \\ 2 Jurusan Teknik Elektro, Universitas Jenderal Achmad Yani, Cimahi 40513 \\ E-mail :naftalin.winanti@lecture.unjani.ac.id
}

\begin{abstract}
ABSTRAK
Perusahaan farmasi adalah salah satu contoh bidang industri yang menggunakan sistem berbasis teknologi dalam proses produksinya. Salah satu sistem yang cukup baik dalam penggunaannya yaitu sistem SCADA. Pada penelitian penulis akan mengembangkan sebuah sistem SCADA (Supervisory Control Acquisition Data) sebagai platform untuk menyelesaikan beberapa masalah yang hadir dalam produksi farmasi yaitu dalam proses produksi obat menggunakan mixing tank hemodilisa.

Metode yang penulis gunakan untuk penelitian ini adalah penelitian eksperimen (percobaan) dan metode pengumpulan data, yang menggunakan variable independen penelitian yaitu water level control dan temperature control sedangkan untuk variable independen terkait dengan hasil baca sistem ditampilkan pada layar SCADA.

Berdasarkan hasil perhitungan matematis didapat kesimpulan bahwa proses produksi menggunkan sistem SCADA menghasilkan waktu yang lebih efisien dengan total perbedaan waktu 38 menit/batch. Operasional menggunakan teknologi SCADA dalam 24 jam mampu memproduksi Bag Infusan sebanyak 4 batch, sedangkan menggunakan sistem konvensional hanya sebanyak 3 batch, hal tersebut menghasilkan kenaikan profit sebesar $32 \%$ dari Rp. 240.000.000/hari menjadi Rp. 320.000.000/hari. Kebutuhan operasional menggunakan teknologi SCADA menghasilkan keuntungan lebih dalam segi biaya maupun waktu, menciptakan sistem kerja yang lebih efektif dan juga efisien bagi perusahaan.
\end{abstract}

Kata Kunci

Mixing tank, Temperature, Water Level, Control, SCADA.

\section{PENDAhuluan}

Kemajuan teknologi berjalan kian cepat seiring dengan berjalannya waktu, revolusi industri 4.0 menjadi salah satu bukti bahwa manusia sudah berhasil mengembangkan teknologi hingga membantu disegala bidang kehidupan. Teknologi sudah membuat manusia mejalani hidup lebih mudah. Selain dalam keseharian, dampak perkembangan teknologi sampai pada pola perekonomian masyarakat, tak terkecuali pola produksi dalam berbagai bidang industri.

Perusahaan farmasi adalah salah satu contoh bidang industri yang menggunakan sistem berbasis teknologi dalam proses produksinya, salah satu sistem yang cukup baik dalam penggunaannya yaitu sistem SCADA. Dengan menggunakan sistem tersebut operator mesin hanya cukup mengawasi jalannya proses produksi, hal ini membuktikan bahwa penggunaan teknologi sudah merambah berbagai macam aspek kehidupan.

Pada penelitian ini penulis akan mengembangkan sebuah sistem SCADA (Supervisory Control Acucition Data) sebagai platform untuk menyelesaikan beberapa masalah yang hadir dalam produksi farmasi yaitu dalam proses produksi obat. Dalam proses produksi obat umumnya perusahaan banyak menggunakan tenaga manusia sebagai power utama dalam hal mobilitas dan pengoprasian, hal ini menyebabkan banyaknya waktu dan biaya yang dibutuhkan, karena metode yang konvensional memerlukan proses yang lebih panjang dalam pekerjaan.

Berdasarkan hal tersebut kami mengembangkan sistem SCADA untuk mengurangi mobilitas operator dalam bekerja agar tidak ada waktu yang terbuang secara percuma serta meningkatkan jumlah produksi karena ada efisiensi waktu, sehingga perusahaan akan mendapatkan income lebih besar karena memaksimalkan waktu dan biaya yang ada.

\subsection{Batasan Masalah}

Dalam perancangan ini penulis hanya meneliti kendali proses secara otomatis dan secara sistem menghitung berapa efisiensi perbandingan dari sistem konvensional terhadap otomatis.

\section{METODE PENELITIAN}

Metode yang penulis gunakan untuk penelitian ini adalah metode eksperimen. Penelitian eksperimen (percobaan) yaitu penelitian mengembangkan inovasi yang berguna dalam meningkatkan kualitas hidup manusia (Gulo, 2002: 20). Sedangkan menurut Sugiyono (2010: 107) metode penelitian ekperimen 
diartikan sebagai metode penelitian yang digunakan untuk mencari pengaruh perlakuan tertentu terhadap yang lain dalam kondisi yang terkendali. Metode eksperimen yang penulis lakukan dalam penelitian ini adalah eksperimen yang dilakukan di PT Sanbe Farma.

\subsection{Variabel Penelitian}

Analisis yang digunakan dalam penelitian ini menggunakan dua variabel penelitian yaitu:

a) Variabel bebas (variabel independen): variabel yang berpengaruh atau menyebabkan berubahnya nilai dari variabel terikat dan merupakan variabel pengaruh yang paling diutamakan dalam penelitian. Variabel bebas penelitian ini adalah variasi water level control dan temperature control.

b) Variabel terikat (variabel dependen): Variabel terikat penelitian ini adalah hasil baca sistem SCADA water level control dan Temperature Control yang di tampilkan pada layar SCADA.

\subsection{Perancangan dan Pembuatan Sistem}

Perancangan sistem dilakukan sebagai langkah awal sebelum terbentuknya suatu sistem beserta rangkaian elektronik pendukungnya yang siap untuk direalisasikan. Hal ini dilakukan agar sistem yang dibuat dapat berjalan sebagaimana mestinya. Perancangan sistem yang dilakukan meliputi:

a) Perancangan Perangkat Keras (hardware). Seperti spesifikasi alat, komponen, pengkabelan, dan merancang penempatan valve.

b) Perancangan Perangkat Lunak (software). Yaitu pembuatan ladder diagram PLC menggunakan cxprogramer, pembuatan desain HMI (Human Machine Interface) menggunakan CX-Supervisory

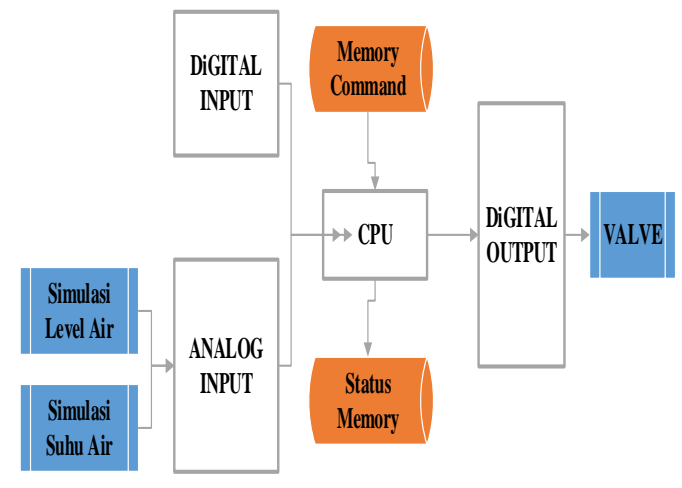

Gambar 1. Diagram Blok Sistem

\subsection{Pengujian Alat}

Untuk memastikan bahwa sistem ini berjalan sesuai dengan perencanaan, maka perlu dilakukan suatu pengujian. Metode pengujian yang dilakukan adalah menguji sistem untuk tiap Mode yang ada pada SCADA dan menguji sistem secara menyeluruh, kemudian menganalisis dari setiap hasil pengujian tersebut. Pengujian ini meliputi:

\section{a) Pengujian Perangkat Keras (Hardware)}

Pengujian perangkat keras dilakukan dengan tujuan untuk menyesuaikan Kondisi apakah Valve bekerja sesuai dengan perintah SCADA dan di uji sampai mana ketangguhan alat yang sedang di uji dari sisi Mekanisme. Pengujian menggunakan Air untuk mengetahui apakah air mengisi seluruh bagian tanki maupun selang dan di cek kembali jangan sampai ada kebocoran.

\section{b) Pengujian Perangkat Lunak (Software)}

Pengujian perangkat lunak dilakukan dengan mengamati tampilan HMI pada layar komputer pada mode runtime. Pengujian perangkat lunak ini meliputi pengujian fungsi tombol tampilan HMI dan kerja program yang telah ditransfer ke PLC.

\section{c) Pengujian Keseluruhan Sistem}

Setelah perangkat keras (hardware) dan perangkat lunak (software) diintegrasikan menjadi satu, kemudian dilakukan pengujian sistem secara keseluruhan dengan mode runtime pada software CX Supervisory. Hal ini bertujuan untuk mengetahui unjuk kerja dari alat tersebut.

\section{HASIL PENGUJIAN DAN ANALISIS}

\subsection{Hasil Akhir Realisasi Alat}

Hasil akhir alat yang dibuat pada penelitian ini meliputi perangkat lunak (software) dan perangkat keras (hardware). Gabungan kedua perangkat inilah yang membentuk sebuah sistem SCADA Mixing Tank.

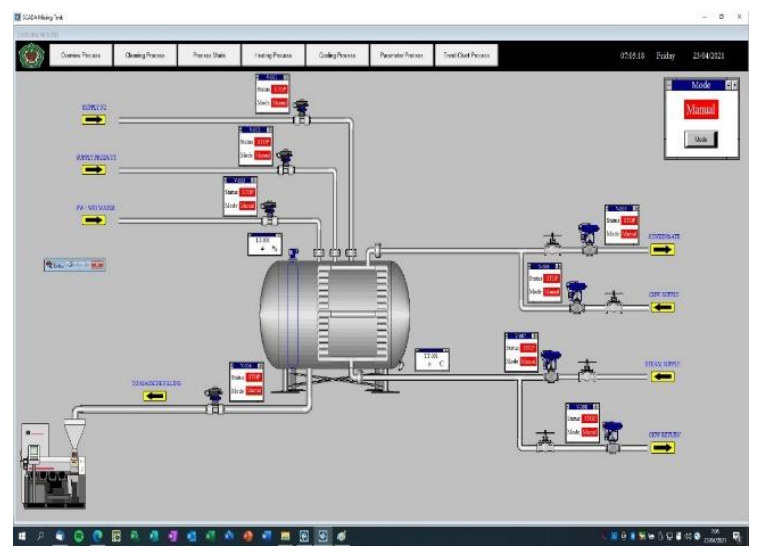

Gambar 2. Tampilan SCADA

Parameter yang digunakan pada system SCADA ada beberapa proses, diantaranya:

1. Cleaning

2. Mixing (pengisian air \& produk)

3. Heating

4. Cooling

5. Mode Transfer (pengosongan) 


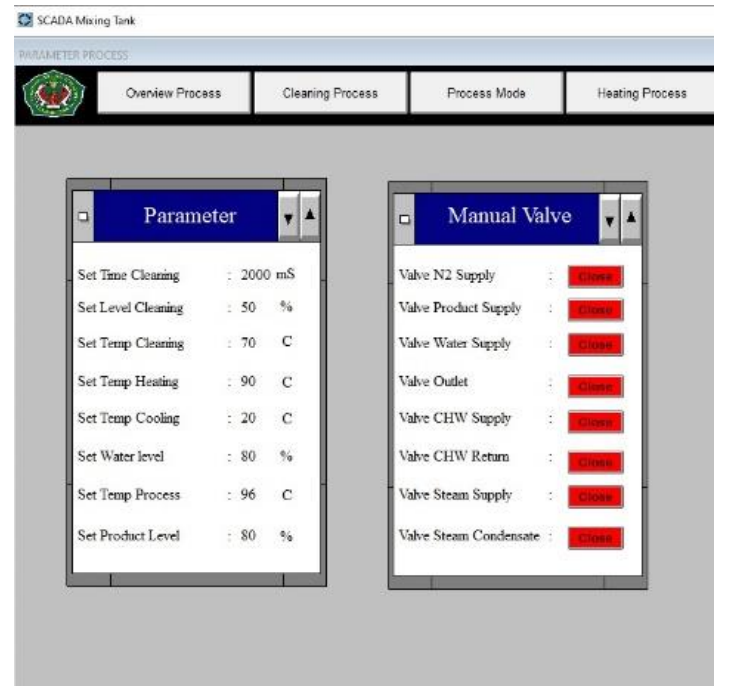

Gambar 3. Tampilan Parameter pada SCADA

Hasil baca sistem SCADA Mixing Tank pada penelitian ini adalah menghitung sebuah lama waktu yang di hasilkan dalam upaya produksi sebuah obat membandingkan lama proses saat menggunakan sistem konvensional dan sistem SCADA. Hal ini dapat menggunakan metode penghitungan Sequential Time yaitu menghitung berapa lama waktu 1 kali proses produksi dan dapat dibuat kesimpulanya dan dikalkulasikan menjadi ouput dan keuntungan.

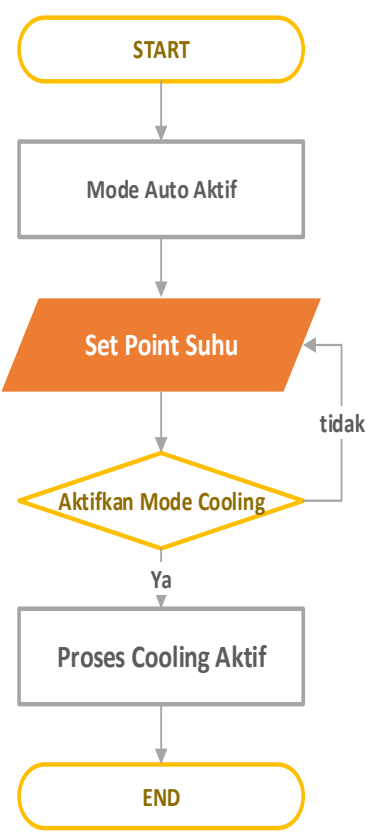

(a)

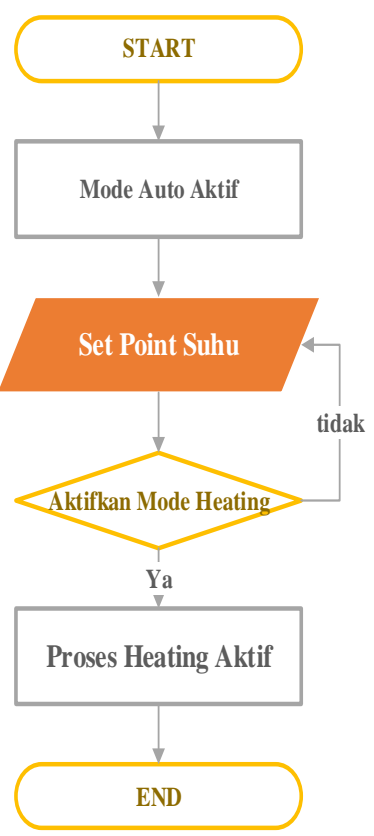

(b)
Gambar 4. Flowchart Cooling (a) dan Heating (b) Proccess.

Pengujian dilakukan dengan membandingkan hasil manual output satu hari ( 3 shiff ) 4 kali mixing tangki 2000 L dengan hasil output automation satu hari ( 3 shiff ) 5 kali mixing tangki $2000 \mathrm{~L}$.

\subsection{Analisis Cooling Proccess}

Hasil Perhitungan matematis dari sebuah analisis Cooling Proses yaitu dapat disimpulkan untuk sistem Konvensional membutuhkan waktu selama \pm 24.30 menit, hal ini dapat dibandingkan antara sistem konvensional dengan sistem SCADA yang hanya membutuhkan waktu \pm 21.00 menit, dapat di simpulkan sistem ini dapat mengefesiensikan waktu selama \pm 3.30 menit hal ini dapat penulis gambarkan dalam sebuah Time Chart.

Cooling Process Konvensional

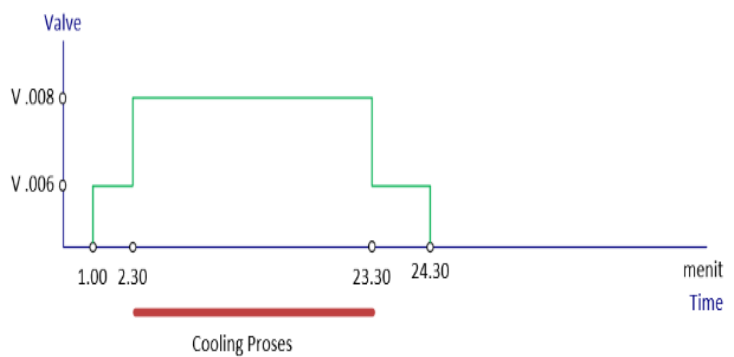

Gambar 5. Time Chart Cooling Proses Konvensional

Cooling Process Sistem SCADA

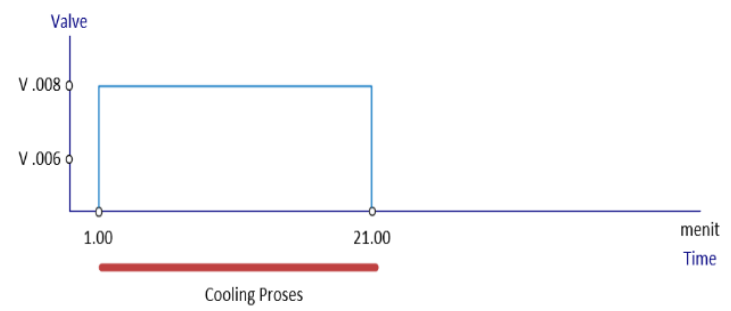

Gambar 6. Time Chart Cooling Proses SCADA

\subsection{Analisis Heating Proccess}

Hasil Perhitungan matematis dari sebuah analisis Heating Proses yaitu dapat disimpulkan untuk sistem Konvensional membutuhkan waktu selama \pm 64.30 menit, hal ini dapat di bandingkan dengan sistem SCADA yang hanya membutuhkan waktu \pm 61.00 menit, dapat di simpulkan bahwasanya sistem ini dapat mengefesiensikan waktu selama \pm 3.30 menit hal ini dapat penulis gambarkan dalam sebuah Time Chart.
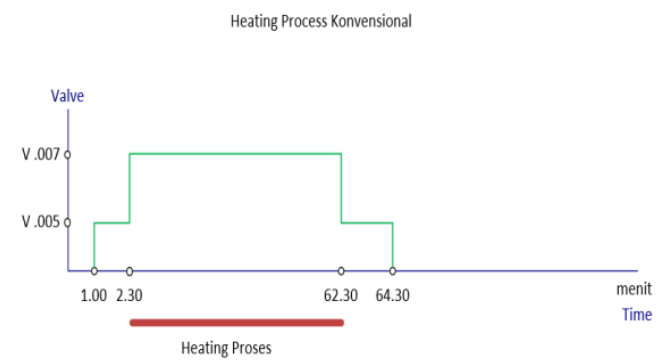

Gambar 7. Time Chart Heating Proses Konvensional Tabel 1. Perbandingan Efisiensi Waktu 


\begin{tabular}{|c|c|c|c|c|}
\hline No & Proses & Konvensional & $\begin{array}{c}\text { Sistem } \\
\text { SCADA }\end{array}$ & Efisiensi \\
\hline 1 & Cleaning & 25 Menit & 10 Menit & 20 Menit \\
\hline 2 & Proses & 201 Menit & 190 Menit & 11 Menit \\
\hline 3 & Cooling & 24.30 Menit & 21 Menit & 3.30 menit \\
\hline 4 & Heating & 64.30 Menit & 61 Menit & 3.30 menit \\
\hline 5 & Prepare & 60 Menit & 60 Menit & 0 menit \\
\hline \multicolumn{2}{|c|}{ Total } & 375 menit & 342 Menit & 38 Menit \\
\hline
\end{tabular}

Heating Process Sistem SCADA

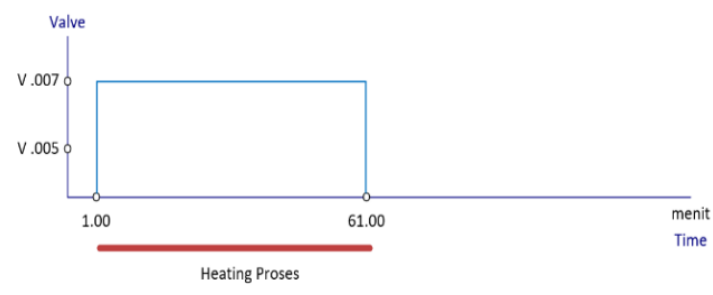

Gambar 8. Time Chart Heating Proses SCADA

\subsection{Analisis Mode Proccess}

Hasil perhitungan matematis dari analisis Mode Proses yaitu dapat di simpulkan untuk sistem Konvensional membutuhkan waktu selama \pm 201.00 menit, hal ini dapat di bandingkan dengan sistem SCADA yang hanya membutuhkan waktu \pm 190.00 menit dapat di simpulkan bahwasanya sistem ini dapat mengefesiensikan waktu selama \pm 11 menit hal ini dapat penulis gambarkan dalam sebuah Time Chart.

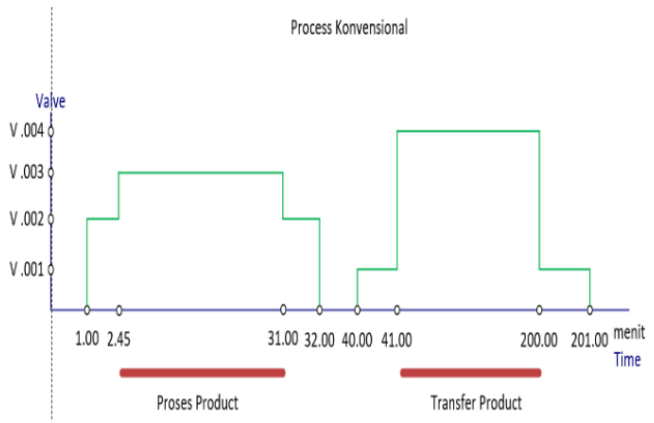

Gambar 9. Time Chart Mode Proses Konvensional

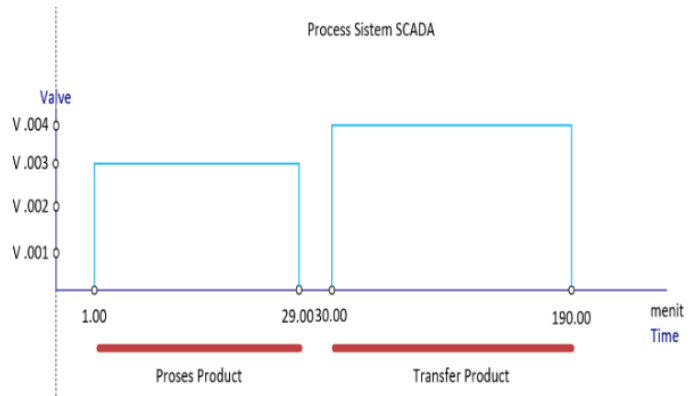

Gambar 10. Time Chart Mode Proses SCADA

\subsection{Analisis Data}

Hasil Perhitungan matematis dari sebuah sistem yaitu dapat disimpulkan untuk sistem Konvensional membutuhkan waktu yang lebih lama jika dibandingkan dengan sistem SCADA, hal tersebut dapat dilihat dalam analisis matematis operasional dalam waktu satu hari penuh hal ini dapat di hitung dengan menggabungkan semua proses menjadi sebuah satu Sequential time yang optimal dan menyeluruh.

- Sistem Konvensional

1 kali Produksi $=375$ Menit $=6,25 \mathrm{Jam} /$ Batch

1 Shift $=8$ Jam

3 Shift $=24$ Jam

3 Shift = 3 Batch

( 19,10 Jam +1 jam Istrahat di setiap Shift )

\section{- Sistem SCADA}

1 kali Produksi $=342$ Menit $=5.7$ Jam $/$ Batch

$\begin{array}{ll}1 \text { Shift } & =8 \mathrm{Jam} \\ 3 \text { Shift } & =24 \mathrm{Jam} \\ 3 \text { Shift } & =4 \text { Batch }\end{array}$

3 Shift $=4$ Batch
$(22,8$ Jam +1 jam Istrahat di setiap Shift $)$

\subsection{Profit Perusahaan}

Harga Produk Infus yang di hasilkan dari Produksi Mesin ini adalah jenis Sanbe RL 500 cc double port dengan Harga terbaru 2021 yaitu sebesar Rp 20.000, dengan ini kita menghitung keuntungan perusahaan dengan menggunakan sistem SCADA adalah :

$$
\begin{array}{ll}
1 \text { Bag infusan } & =500 \mathrm{cc} / \frac{\mathbf{1}}{\mathbf{2}} \text { Liter } \\
1 \text { Tank } & =\mathbf{2 0 0 0} \text { Liter } \\
1 \text { Tank } & =4000 \mathrm{Bag} \text { Infusan }
\end{array}
$$

Dengan ini hasil dari perhitungan 1 kali Produksi/Batch adalah 4000 Bag Infusan dengan ini penulis dapat menghitung keuntungan perusahaan yaitu :

$$
\begin{array}{ll}
1 \text { Bag infusan } & =\operatorname{Rp} 20.000 \\
4000 \text { Bag Infusan } & =\text { Rp } 80.000 .000 / \text { Batch }
\end{array}
$$

Dari perhitungan tersebut didapatkan keuntungan jika sistem SCADA digunakan yaitu sebesar Rp 320.000.000 dalam 3 Shift, dan jika menggunakan sistem Konvensional yang hanya dapat menghasilkan Rp 240.000.000 dalam 3 Shift, hal ini di dapatkan selisih keuntungan sebesar Rp 80.000.000 dari 3 shift kerja/24 Jam kerja normal.

\section{KESIMPULAN}

Telah dibuat suatu sistem berbasis SCADA pada mixing tank hemodialisa di PT Sanbe Farma menggunakan cx-programer dan cx-supervisory.

Proses produksi menggunkan sistem SCADA menghasilkan waktu yang lebih efisien dengan total perbedaan waktu 38 menit/batch. 
Operasional menggunakan teknologi SCADA dalam 24 jam mampu memproduksi Bag Infusan sebanyak 4 batch, sedangkan menggunakan sistem konvensional hanya sebanyak 3 batch.

$\checkmark$ Sistem SCADA dapat menghasilkan kenaikan profit sebesar $32 \%$ dari Rp. 240.000.000/hari menjadi Rp. 320.000.000/hari.

\section{UCAPAN TERIMA KASIH}

Penulis ucapkan terima kasih kepada PT Sanbe Farma yang telah memberi izin dan fasilitas untuk melakukan eksperimen penelitian ini.

Juga kepada Jurusan Teknik Elektro Universitas Jenderal Achmad Yani yang telah sepenuhnya mendukung penelitian ini.

\section{DAFTAR PUSTAKA}

[1] Bolton, William. (2003). Programmable Logic Controller. Jakarta:Erlangga.

[2] Dikdik Widianto, Eko. (2017). Teknologi Sistem Komputer. Semarang: Universitas Diponegoro.

[3] Ike B, Caroline. (2013). 'Perancangan sistem pemantauan Pengendali Suhu pada Stirred Tank Heater menggunakan Supervisory Control and Data Acquisition (SCADA). Jurnal Rekayasa Elektrika Vol.10 Nomor 3. Pp 115-159.

[4] Iwan Setiawan. (2006). Programmable Logic Controller $(P L C)$ \& Teknik Perancangan Sistem Kontrol. Yogyakarta: Andi.

[5] Kitoma Indonesia. (2021). Definisi Valve, Jenis dan Fungsinya.

[6] Nursalim, (2018). 'SCADA Pada Plant Generator Heater menggunakan Adam 6066-6017 sebagai implementasi era Industri 4.0'. 9th Industrial Research Workshop and National Seminar.

[7] Yefta NS, Handy. (2013). 'Sistem SCADA Berbasis Internet untuk Model Otomasi Bangunan'. Jurnal Dimensi Teknik Elektro Vol. 1 No. 1, pp 18-23.

[8] Yulianto, Erwin. 2019. Pembangunan Informasi Fasilias Kepegawian Berbsis Multimedia Menggunakan Industrial PC. Bandung: Universitas Langlangbuana. 